\title{
Velocidade do ar em barra de pulverização na deposição da calda fungicida, severidade da ferrugem asiática e produtividade da soja
}

\author{
Evandro Pereira Prado ${ }^{1,2}$, Carlos Gilberto Raetano ${ }^{1}$, Hélio Oliveira Aguiar Júnior ${ }^{1}$, Mário Henrique Ferreira do \\ Amaral Dal Pogetto ${ }^{1}$, Rafael de Souza Christovam¹, Marcelo Júnior Gimenes ${ }^{1}$, Demétrius de Araújo ${ }^{1}$
}

${ }^{1}$ Faculdade de Ciências Agronômicas/UNESP-Departamento de Produção Vegetal-Defesa Fitossanitária-Caixa Postal 237, 18610-307 Fone: (14) 3811-7167 Botucatu/SP. ${ }^{2}$ Bolsista CNPq, parte da dissertação de mestrado do primeiro autor.

Autor para correspondência: Evandro Pereira Prado (epprado@hotmail.com )

Data de chegada: 06/04/2009. Aceito para publicação em: 19/08/2009.

\section{RESUMO}

Prado, E.P.; Raetano, C.G.; Aguiar Júnior, H.O.; Dal Pogetto, M.H.F.A.; Christovam, R.S.; Gimenes, M.J.; Araújo, D. Velocidade do ar em barra de pulverização na deposição da calda fungicida, severidade da ferrugem asiática e produtividade da soja. Summa Phytopathologica, v.36, n.1, p.45-50, 2010 .

O trabalho objetivou comparar a deposição da pulverização e o controle da ferrugem asiática após o tratamento com fungicidas sob quatro velocidades da assistência de ar junto à barra de pulverização na cultura da soja. Dois experimentos foram conduzidos na FCA/ UNESP - Campus de Botucatu, safra 2006/07. Alvos artificiais foram fixados na superfície adaxial e abaxial de folíolos posicionados nas partes superior e inferior das plantas selecionadas e distribuídas perpendicularmente ao deslocamento do pulverizador. O oxicloreto de cobre (50\% de cobre metálico) foi o marcador utilizado em pulverização e a determinação quantitativa dos depósitos feita com o uso de espectrofotometria de absorção atômica. Após a aplicação do fungicida piraclostrobina + epoxiconazole sob diferentes velocidades da assistência de ar junto à barra de pulverização $\left(0,9,11\right.$ e $\left.29 \mathrm{~km} \mathrm{~h}^{-1}\right)$ procedeu-se a avaliação da severidade da doença e produtividade da soja. $\mathrm{Na}$ parte superior das plantas os maiores níveis de depósitos foram encontrados na pulverização sem assistência de ar. Já na parte inferior da planta foram encontrados os maiores níveis de deposição quando foram utilizadas as maiores velocidades da assistência de ar. No geral, a severidade da doença foi mais acentuada nos tratamentos sem o uso da assistência de ar. Em relação à produtividade não houve diferenças entre os tratamentos com aplicação de fungicidas, porém houve incremento na produtividade para os tratamentos com assistência de ar.

Palavras-chave adicionais: Tecnologia de aplicação, deposição, ferrugem da soja, assistência de ar.

\section{ABSTRACT}

Prado, E.P.; Raetano, C.G.; Aguiar Júnior, H.O.; Dal Pogetto, M.H.F.A.; Christovam, R.S.; Gimenes, M.J.; Araújo, D. Effect of the Air Speed in Sleeve Boom on Pesticide Spray Deposition, Severity and Soybean Crop Yield. Summa Phytopathologica, v.36, n.1, p.45-50, 2010.

This research aimed to evaluate the effects of chemical control of the rust and deposition fungicide sprayed under four air speed in spray boom on soybean crop (Glycine $\max$ L.). Two experiments were carried out in FCA/UNESP-Botucatu/SP (season 2007/08). The tracer used in the spray solution was copper oxychloride (50\% of the metallic copper). It was measured by spectrophotometer of atomic absorption equipment. The targets were fixed on the under and upper side of the leaflets, in the top and lower parts of the same plant under the spray boom (experiment 1). After the application of pyraclostrobin + epoxiconazole fungicide mixture with the differents air speed $\left(0,9,11\right.$ and $\left.29 \mathrm{~km} \mathrm{~h}^{-1}\right)$ rust severity and crop yield were evaluated (experiment 2). Significant differences were obtained in the lower part of the plants for spray deposition using higher speed of air assisted. In the top of the plants were found the great levels of deposition when used spraying without air-assisted. The rust severity was more intense in treatments without air-assisted. The crop yield did not show differences between the treatments with fungicide application, but with advantage to the air-assisted sprayer.

Keywords: Application technology, deposition, soybean rust, air assisted.

A ferrugem asiática da soja [Glycine max (L.) Merrill causada pelo fungo Phakopsora pachyrhizi Sydow \& Sydow foi relatada pela primeira vez no Brasil no final da safra 2001/02 (21). Desde então, essa doença passou a ser motivo de preocupações para os sojicultores de todo o Brasil, pois se não controlada propicia enormes perdas na produtividade e na qualidade dos grãos de soja.

Embora os produtos fitossanitários desempenhem papel importante e em muitos casos insubstituíveis, no sistema de produção agrícola, tem sido motivo de inúmeras discussões a respeito do seu potencial de risco ambiental e para a saúde humana. Em muitos casos esses problemas podem ser minimizados com a tecnologia adequada de aplicação desses produtos. Entretanto, o que se observa na prática é a falta de informação dos agricultores a respeito da técnica de aplicação que propicie menor exposição dos aplicadores e do ambiente.

No controle químico de pragas, doenças e plantas daninhas, dá-se muita importância ao produto e pouca atenção a técnica de aplicação. A consequência é a perda de eficácia, quando não o fracasso total do tratamento, com superdosagens e subdosagens que levam a perda de rentabilidade dos cultivos e danos ao ambiente (8).

Segundo Raetano (18), a ferrugem da soja $P$. pachyrhizi manifesta 
os sintomas iniciais no terço inferior do dossel da cultura. Sendo assim, as aplicações de fungicidas devem vencer a barreira imposta pela massa de folhas, objetivando promover melhor cobertura nessa parte da planta. Aliado a isso, muitos fungicidas sistêmicos em plantas dicotiledôneas como a soja, apresentam uma ação locossistêmica, ou seja, são translocados somente a pequenas distâncias dentro da folha, necessitando de boa cobertura para que seja obtida sua máxima eficiência (1). Portanto a tecnologia de aplicação constitui fator diferencial para obtenção de melhor eficiência de controle desse patógeno.

Cunha \& Ruas (8) estudando a cobertura propiciada por diferentes pontas de pulverização constataram que as pontas de jato plano padrão apresentaram depósitos médios superiores nas partes inferiores do dossel das plantas de soja quando comparadas às pontas de jato plano de pré-orifício, jato plano duplo de indução de ar e jato plano de indução de ar, as quais são recomendadas para situações onde há necessidade de controle da deriva.

$\mathrm{O}$ uso de pulverizadores dotados de assistência de ar junto à barra de pulverização pode minimizar as perdas por deriva com pontas de pulverização que produzem gotas finas. Dessa forma, a assistência de ar possibilita o uso de gotas finas com maior eficiência, pela redução da deriva e maiores depósitos sobre o alvo, além de possibilitar maior penetração dessas gotas em culturas mais enfolhadas com reduções das perdas para o solo $(2,15)$.

O objetivo da assistência de ar é aumentar a velocidade da gota pulverizada e modificar a sua trajetória melhorando a deposição, reduzindo o potencial de deriva bem como a contaminação pelo produto de organismos não-alvo (14).

Nos últimos anos pesquisas referentes a essa tecnologia tem sido intensificadas $(2,3,4,7,16,17,20)$, demonstrando os benefícios da assistência de ar em pulverizadores de barras.

Outra vantagem que o uso da assistência de ar pode oferecer é que pulverizadores dotados dessa tecnologia reduzem os custos com aplicações de produtos fitossanitários, uma vez que eles podem reduzir o volume de aplicação e, consequentemente, aumentar a capacidade operacional do equipamento (19).

Apesar de vários trabalhos demonstrarem-na como uma tecnologia mais favorável quanto à penetração da calda no dossel das partes inferiores das plantas de soja $(2,4)$, poucos são os estudos referentes a eficiência dos fungicidas pulverizados com o auxílio dessa tecnologia. Sendo assim, o presente trabalho teve como objetivos avaliar a deposição da pulverização nas plantas de soja, em função de diferentes velocidades da assistência de ar junto à barra de pulverização, bem como o efeito dessa tecnologia no controle da ferrugem asiática da soja em condições de campo.

\section{MATERIAL E MÉTODOS}

\section{Experimento 1}

O experimento foi conduzido na safra 2007/08, em área experimental da fazenda de Ensino, Pesquisa e Produção (FEPP) da FCA/UNESP - Campus de Botucatu (22 $48^{\circ} 59,7^{\prime \prime} \mathrm{S}$ e $48^{\circ} 25^{\prime} 38,2^{\prime \prime}$ W) na cultura da soja, cultivar Conquista. A semeadura da soja foi realizada no dia 23/11/2007 com espaçamento de 0,45 metros entre linhas com uma densidade de 18 sementes $\mathrm{m}^{-1}$ conduzida em sistema de semeadura direta. No dia 22/11/07 fez-se a dessecação da Aveia preta (Avena strigosa Schreb) utilizada como cultura de inverno, com o herbicida glifosate ( $2,0 \mathrm{~kg}$ do i.a. ha $\mathrm{h}^{-1}$ ) e diclosulam (35 g do i.a. ha-1). A adubação foi feita no sulco de semeadura com $320 \mathrm{~kg} \mathrm{ha}^{-}$
${ }^{1}$ da formulação comercial de N-P-K (04 20 20).

$\mathrm{O}$ ensaio foi conduzido no delineamento experimental em blocos ao acaso com 4 tratamentos e 5 repetições, onde foram testadas 4 velocidades da assistência de ar na barra de pulverização $(0,9,11$ e $29 \mathrm{~km} \mathrm{~h}^{-1}$ ). Para avaliação dos depósitos da pulverização foram colocados em cada parcela alvos artificiais (papel filtro com dimensões de $3 \times 3 \mathrm{~cm}$ ) distribuídos em 10 plantas tomadas ao acaso. Em cada uma das 10 plantas amostradas foram fixados quatro coletores (papel filtro), um na superfície adaxial e outro na superfície abaxial do mesmo folíolo nas partes superior e inferior da mesma planta.

Para mensurar os depósitos utilizou-se um fungicida cúprico à base de oxicloreto de cobre (Cobox 50\%), como marcador, na concentração de $250 \mathrm{~g} 100 \mathrm{~L}^{-1}$, pulverizado aos 86 dias após a emergência (DAE), com a cultura no estádio reprodutivo $R_{2}$ (10).

A regulagem da velocidade de ar gerada junto à barra de pulverização foi feita pelo número de voltas do dispositivo controlador da rotação do ventilador, adotando-se as velocidades de 0 (rotação do ventilador desligada), 9, 11 e $29 \mathrm{~km} \mathrm{~h}^{-1}$ da velocidade do ar gerada pelo ventilador (sentido horário aumenta e sentido anti-horário diminui a velocidade do ar), onde o número máximo de voltas dada no dispositivo proporciona velocidade de ar de $29 \mathrm{~km} \mathrm{~h}^{-1}$ no equipamento Advanced Vortex 2000. O pulverizador estava equipado com barra de pulverização de $18,5 \mathrm{~m}$ de comprimento e 37 pontas de pulverização de jato plano XR 8002 , à pressão de $400 \mathrm{kPa}$. A barra foi mantida sempre a $0,5 \mathrm{~m}$ de altura em relação às plantas de soja com uma velocidade de deslocamento do conjunto trator-pulverizador de $7,2 \mathrm{~km} \mathrm{~h}^{-1}$ conferindo um volume de $150 \mathrm{~L} \mathrm{ha}^{-1}$.

No momento da pulverização do traçador cúprico, as condições ambientais foram: temperatura de 29,0 $\pm 2{ }^{\circ} \mathrm{C}$; umidade relativa do ar de $60 \pm 10 \%$ e velocidade do vento oscilando entre 5 a $8 \mathrm{~km} \mathrm{~h}^{-1}$ no sentido Oeste, perpendicular ao sentido de caminhamento do pulverizador, iniciando às $11 \mathrm{~h} 40 \mathrm{~min}$. e finalizando às $12 \mathrm{~h} 30 \mathrm{~min}$.

Após o término da pulverização, os alvos artificiais (papel filtro) foram retirados dos folíolos e colocados em frascos de vidro (capacidade de $30 \mathrm{~mL}$ ) contendo $20 \mathrm{~mL}$ de solução extratora de ácido nítrico a $1,0 \mathrm{Mol} \mathrm{L}^{-1} \mathrm{e}$, após 15 minutos de agitação constante na velocidade de $220 \mathrm{rpm}$ e 24 horas de descanso, as soluções de lavagem foram levadas ao espectrofotômetro de absorção atômica para quantificação do íon cobre $(\mathrm{Cu})$, conforme metodologia descrita por Chaim et al. (6).

Considerando que a concentração de cobre na calda foi de $1226,34 \mathrm{mg} \mathrm{L}^{-1}$, foi possível o estabelecimento do volume líquido capturado através da equação 1:

$\mathrm{C}_{\mathrm{i}} \times \mathrm{V}_{\mathrm{i}}=\mathrm{C}_{\mathrm{f}} \times \mathrm{V}_{\mathrm{f}} \quad$ (Equação 1)

Em que $\mathrm{C}_{\mathrm{i}}=$ Concentração de cobre na calda $\left(\mathrm{mg} \mathrm{L}^{-1}\right)$

$\mathrm{C}_{\mathrm{f}}=$ Concentração de cobre detectada no espectrofotômetro de absorbância atômica $\left(\mathrm{mg} \mathrm{L}^{-1}\right)$

$\mathrm{V}_{\mathrm{i}}=$ Volume capturado pelo alvo $(\mathrm{mL})$

$\mathrm{V}_{\mathrm{f}}=$ Volume da diluição da $\operatorname{amostra}(\mathrm{mL})$.

Para análise estatística dos valores médios dos depósitos, foi considerado o delineamento em blocos casualizados no esquema fatorial 4 × 2 (quatro velocidades do ar em duas posições de amostragem, abaxial e adaxial) nas partes superior e inferior das plantas.

Os valores dos depósitos nos coletores artificiais foram submetidos à análise de variância pelo teste $\mathrm{F}$ e as médias comparadas pelo teste de Duncan a $5 \%$ de probabilidade. 


\section{Experimento 2}

O experimento foi conduzido na mesma cultura e local do experimento 1 , no delineamento experimental em blocos ao acaso com 5 tratamentos e 4 repetições, onde foram testadas 4 velocidades da assistência de ar junto à barra de pulverização $(0,9,11$ e $29 \mathrm{~km}$ $\mathrm{h}^{-1}$ ) mais testemunha, onde não foi realizada nenhuma aplicação de fungicida. Os equipamentos e sua calibração foram os mesmos utilizados no experimento 1 .

Quando a cultura entrou no estádio de desenvolvimento reprodutivo, foram realizados levantamentos semanais para monitoramento da infestação natural da ferrugem asiática, causada pelo fungo Phakopsora pachyrhizi. Para avaliação da infestação da doença foram observados os folíolos da parte inferior das plantas de soja e, quando confirmada a presença da doença $\left(R_{2}\right)$, procedeuse a primeira aplicação de fungicida.

$\mathrm{Na}$ primeira aplicação (25/02) da mistura fungicida piraclostrobina + epoxiconazole (Suspensão Emulsionável) na dosagem de $66,5+25$ g i.a. ha ${ }^{-1}$, a cultura encontrava-se no estádio reprodutivo $\mathrm{R}_{2}(98 \mathrm{DAE})$ e as condições ambientais foram: temperatura de $28,0 \pm 2{ }^{\circ} \mathrm{C}$; umidade relativa do ar de $57 \pm 5 \%$ e velocidade do vento oscilando entre 5 a $7 \mathrm{~km} \mathrm{~h}^{-1}$, no período de $16 \mathrm{~h} 00 \mathrm{~min}$ às $16 \mathrm{~h} 35 \mathrm{~min}$.

Na segunda aplicação (10/03), utilizou-se o mesmo fungicida da primeira aplicação, na dosagem de $66,5+25$ g i.a. ha ${ }^{-1}$, quando a cultura estava no estádio $\mathrm{R}_{5.2}(112 \mathrm{DAE})$ e as condições ambientais foram: temperatura de $27,0 \pm 2{ }^{\circ} \mathrm{C}$; umidade relativa do ar de $63 \pm$ $5 \%$ e velocidade do vento oscilando entre 6 a $8 \mathrm{~km} \mathrm{~h}^{-1}$, iniciando às $9 \mathrm{~h} 40 \mathrm{~min}$ até $10 \mathrm{~h} 15 \mathrm{~min}$.

A avaliação da eficácia do fungicida (piraclostrobina + epoxiconazole) no controle da ferrugem da soja, considerando as quatro velocidades da assistência de ar junto à barra de pulverização, foi feita mediante a comparação da severidade da doença, peso de 1000 sementes e da produtividade entre parcelas tratadas com fungicida e parcelas não-tratadas (testemunha).

A avaliação da severidade da ferrugem foi realizada a intervalos de aproximadamente 7 dias, totalizando cinco avaliações. A primeira avaliação da severidade foi feita aos 94 (DAE). Para tal, foram atribuídas após observação visual notas de porcentagem de área lesionada pela doença $(0,6 ; 2,0 ; 7,0 ; 18,0 ; 42,0$ e 78,5\%) utilizando a escala diagramática proposta por Godoy et al. (13).

Com os dados da severidade da doença, procedeu-se à construção da curva de progresso e à determinação da área abaixo da curva de progresso da ferrugem (AACPF). Essa foi calculada pelo somatório das áreas trapezoidais, conforme metodologia proposta por Campbell \& Madden (5).

Para avaliação do efeito da assistência de ar no controle da ferrugem asiática sobre a produtividade da soja, foi realizada a colheita dentro de cada parcela, sendo colhidas 3 linhas com 8 metros de comprimento, com auxílio de uma colhedora de parcelas. Após a colheita, fez-se a correção da umidade dos grãos para $13 \%$ (b.u.), os quais foram pesados e os valores foram estipulados em $\mathrm{kg} \mathrm{ha}^{-1}$. Após medida a produção, foi feita a pesagem da massa de 1000 grãos. O controle de insetos-praga da soja, lagartas desfolhadoras e percevejos, foram realizados sempre que estes atingiram o nível de dano econômico da cultura.

Os dados de severidade da doença, massa de 1.000 grãos e produtividade foram submetidos à análise de variância, e as médias das parcelas tratadas com fungicidas foram comparadas à testemunha, pelo teste de Duncan a 5\% de significância, utilizando o programa computacional Assistat (11).

\section{RESULTADOS E DISCUSSÃO}

\section{Experimento 1}

A utilização da espectrofotometria de absorção atômica permitiu obter valores médios de recuperação, para o elemento cobre superiores a $99 \%$ para os alvos em análises.

Os resultados do volume de calda capturados em diferentes posições da planta são mostrados na Tabela 1. O tratamento convencional (sem assistência de ar) e com a velocidade de $9 \mathrm{~km} \mathrm{~h}^{-1} \mathrm{da}$ velocidade do ar apresentaram depósitos médios significativamente maiores em comparação ao tratamento com velocidade de $11 \mathrm{~km} \mathrm{~h}^{-1}$ na parte superior das plantas e superfície adaxial dos folíolos de soja. Já na superfície abaxial da parte superior da planta, os depósitos não apresentaram diferenças significativas. Christovam (7) obteve resultados semelhantes em relação aos depósitos da parte superior da planta na superfície abaxial dos folíolos de soja.

Tabela 1. Valores médios dos depósitos de um marcador cúprico, em diferentes partes da planta e superfícies dos folíolos de soja, após a pulverização com diferentes velocidades de ar gerada pelo ventilador. Botucatu-SP, 2008.

\begin{tabular}{|c|c|c|c|c|}
\hline \multirow{3}{*}{$\begin{array}{l}\text { Velocidade do } \\
\text { Ar }\left(\mathrm{km} \mathrm{h}^{-1}\right)\end{array}$} & \multicolumn{2}{|c|}{ Superior } & \multicolumn{2}{|c|}{ Inferior } \\
\hline & Adaxial & Abaxial & Adaxial & Abaxial \\
\hline & \multicolumn{2}{|c|}{$\mu \mathrm{L} \mathrm{cm}{ }^{-2}$} & \multicolumn{2}{|c|}{$\mu \mathrm{L} \mathrm{cm}{ }^{-2}$} \\
\hline 0 & 1,9437 a $\mathrm{A}$ & 0,7088 a $\mathrm{B}$ & 0,4404 b A & 0,2371 a $A$ \\
\hline 9 & $1,7239 \mathrm{ab} A$ & 0,3901 a B & 0,7088 b A & 0,3576 a $\mathrm{A}$ \\
\hline 11 & 0,4034 с A & 0,2554 a $\mathrm{A}$ & 2,0485 a A & 0,3231 a $B$ \\
\hline 29 & $1,0603 \mathrm{bc} \mathrm{A}$ & 0,4532 a $\mathrm{A}$ & $1,5044 \mathrm{ab} A$ & 0,4863 a $\mathrm{B}$ \\
\hline \multicolumn{5}{|l|}{$\overline{\mathrm{DMS}}$} \\
\hline $\begin{array}{l}\text { (Velocidade do ar) } \\
\text { DMS }\end{array}$ & \multicolumn{2}{|c|}{0,8356} & \multicolumn{2}{|c|}{1,0702} \\
\hline (Posição na planta) & \multicolumn{2}{|c|}{0,6267} & \multicolumn{2}{|c|}{0,8028} \\
\hline C.V.(\%) & \multicolumn{2}{|c|}{55,74} & \multicolumn{2}{|c|}{81,13} \\
\hline
\end{tabular}

Médias seguidas de mesma letra minúscula na coluna e maiúscula na linha, não diferem estatisticamente pelo teste de Duncan a $5 \%$ de probabilidade.

Comparando a superfície adaxial com a abaxial da parte superior da planta (Tabela 1), os tratamentos sem assistência de ar e com ar operando na velocidade de $9 \mathrm{~km} \mathrm{~h}^{-1}$ apresentaram as maiores médias de depósitos na superfície adaxial. Isso demonstra que na ausência do ar maiores depósitos ficaram na parte superior da planta.

Com relação à deposição na parte inferior da planta (Tabela 1), verifica-se maior deposição do produto cúprico na superfície adaxial dos folíolos na velocidade de $11 \mathrm{~km} \mathrm{~h}^{-1}$, diferindo estatisticamente do tratamento sem assistência de ar e com ar na velocidade de $9 \mathrm{~km} \mathrm{~h}^{-1}$. O efeito da assistência de ar proporcionou significativo aumento dos níveis de depósitos na superfície adaxial dos folíolos posicionados na parte inferior da planta. Os depósitos encontrados na superfície abaxial da parte inferior da planta não diferiram estatisticamente entre si, porém o tratamento com a velocidade máxima na barra de pulverização apresentou o maior valor de depósito.

Raetano e Bauer (16), estudaram diferentes velocidades da assistência de ar junto à barra de pulverização e concluíram que a utilização da assistência de ar, operando a plena capacidade do ventilador com a ponta de jato plano AXI 110015, resultou em melhores níveis de depósitos na superfície abaxial dos folíolos inferiores da cultura do feijoeiro.

Comparando a deposição entre superfície adaxial e abaxial da parte inferior da planta, apenas os tratamentos com velocidade do ar de 11 $\mathrm{km} \mathrm{h}^{-1}$ e $29 \mathrm{~km} \mathrm{~h}^{-1}$ apresentaram valores médios de depósitos significativamente menores na superfície abaxial dos folíolos (Tabela 
1). Os valores menores dos depósitos na superfície abaxial dos folíolos em presença da assistência de ar em maiores velocidades, provavelmente devem-se à interceptação das gotas pela superfície adaxial e, dessa forma, menor número de gotas se depositaria na superfície abaxial.

Os valores médios dos depósitos da parte superior e inferior da planta estão demonstrados na Tabela 2. Observa-se maior deposição na parte superior da planta no tratamento convencional (sem ar). $\mathrm{Na}$ parte inferior da planta, os tratamentos com assistência de ar apresentaram os maiores valores médios de depósitos, mas somente o tratamento com velocidade do ar operando a $11 \mathrm{~km} \mathrm{~h}^{-1}$ apresentou valores significativamente maiores. Comparando a deposição entre a parte superior e inferior da planta, nota-se que o tratamento convencional apresentou os maiores valores de deposição na parte superior da planta quando comparado àqueles obtidos na parte inferior, diferindo significativamente entre si. O contrário aconteceu com o tratamento na velocidade de $11 \mathrm{~km} \mathrm{~h}^{-1}$ que diferiu significativamente apresentando maiores valores de deposição na parte inferior da planta.

Tabela 2. Valores médios dos depósitos de um marcador cúprico nos folíolos de soja das partes inferior e superior da planta após pulverização com diferentes velocidades de ar gerada pelo ventilador. Botucatu-SP, 2008.

\begin{tabular}{lcc}
\hline \multirow{2}{*}{$\begin{array}{c}\text { Velocidade } \\
\text { do } \mathrm{Ar}\left(\mathrm{km} \mathrm{h}^{-1}\right)\end{array}$} & \multicolumn{2}{c}{ Posição de amostragem na planta } \\
\cline { 2 - 3 } & \multicolumn{2}{c}{ Superior } \\
\cline { 2 - 3 } 0 & $2,6525 \mathrm{a} \mathrm{A}$ & $0,6717 \mathrm{~b} \mathrm{~B}$ \\
9 & $2,1141 \mathrm{ab} \mathrm{A}$ & $1,0665 \mathrm{ab} \mathrm{A}$ \\
11 & $0,6588 \mathrm{~b} \mathrm{~B}$ & $2,3716 \mathrm{a} \mathrm{A}$ \\
29 & $1,5135 \mathrm{ab} \mathrm{A}$ & $1,9907 \mathrm{ab} \mathrm{A}$ \\
\hline
\end{tabular}

\section{DMS}

(Velocidade do ar)

1,6318

DMS

(Posição na planta) $\quad 1,2240$

C.V. $(\%)$

57,93

Médias seguidas de mesma letra minúscula na coluna e maiúscula na linha, não diferem estatisticamente pelo teste de Duncan a $5 \%$ de probabilidade

Cunha et al. (9) avaliaram o efeito de pontas de pulverização no controle químico da ferrugem asiática com pulverizadores convencionais (sem assistência de ar) e observaram que a deposição na parte superior da planta foi muito maior que na parte inferior, atribuindo o resultado ao fechamento da cultura da soja. O mesmo autor relata que esse tipo de aplicação pode não ser eficiente no caso de doenças que tenham o seu desenvolvimento inicial na parte baixeira das plantas, comprometendo o desempenho do fungicida empregado.

Bauer et al. (4) avaliaram a deposição das pontas de pulverização AXI 11002 e JA-2 em diferentes condições operacionais na cultura da soja no estádio de desenvolvimento reprodutivo $R_{2}$ e observaram que os tratamentos dotados de assistência de ar apresentaram as menores médias de depósito na parte superior das plantas em comparação aos tratamentos ausentes dessa tecnologia. Porém, no estádio $\mathrm{R}_{5,2}$ tal diferença não foi detectada.

Nos tratamentos com velocidades do ar junto à barra de pulverização, ocorre o contrário com valores médios de deposição maiores na parte inferior da planta em comparação com a parte superior. De acordo com Bauer \& Raetano (2) as possíveis razões para a ocorrência desse fato são o aumento da velocidade das gotas e a maior movimentação das folhas nessas posições, podendo influenciar positivamente na captura das gotas pelas folhas, proporcionando maiores níveis de depósitos. Essa maior penetração e deposição da calda de pulverização com auxílio da assistência de ar pode aumentar a eficiência de controle de doenças na cultura da soja, que possuem o início do seu desenvolvimento nas folhas da parte inferior da cultura como é o caso da ferrugem asiática $P$. pachyrhizi.

\section{Experimento 2}

$\mathrm{O}$ efeito das velocidades da assistência de ar junto à barra de pulverização no controle do patógeno, representado pela área abaixo da curva de progresso da ferrugem (AACPF), encontra-se na Tabela 3. $\mathrm{Na}$ avaliação realizada aos 94 dias após a emergência (DAE), os tratamentos com as velocidades de 11 e $29 \mathrm{~km} \mathrm{~h}^{-1}$ apresentaram diferenças estatística quando comparados ao tratamento testemunha.

Tabela 3. Severidade média por Phakopsora pachyrhizi, representada pelos valores abaixo da área da curva de progresso da ferrugem (AACPF), na cultura da soja, antes e após 2 aplicações $(R$ e $R$ ) da mistura fungicida piraclostrobina + epoxiconazole. Botucatu-SP̉, safrá 2007/2008.

\begin{tabular}{lllllll}
\hline $\begin{array}{l}\text { Velocidade } \\
\text { do } \mathbf{A r}\left(\mathbf{k m ~ h}^{-1}\right)\end{array}$ & \multicolumn{6}{c}{ Dias após a emergência } \\
\cline { 2 - 8 } & $\mathbf{9 4}$ & $\mathbf{1 0 3}$ & $\mathbf{1 0 8}$ & $\mathbf{1 1 5}$ & $\mathbf{1 2 3}$ & Total \\
\hline 0 & $14,7 \mathrm{ab}$ & $31,5 \mathrm{a}$ & $62,1 \mathrm{a}$ & $223,4 \mathrm{~b}$ & $257,3 \mathrm{~b}$ & $589,0 \mathrm{~b}$ \\
9 & $17,8 \mathrm{ab}$ & $38,7 \mathrm{a}$ & $59,0 \mathrm{a}$ & $163,4 \mathrm{~b}$ & $135,2 \mathrm{a}$ & $414,2 \mathrm{~b}$ \\
11 & $8,1 \mathrm{a}$ & $26,9 \mathrm{a}$ & $57,5 \mathrm{a}$ & $163,9 \mathrm{~b}$ & $159,0 \mathrm{a}$ & $415,3 \mathrm{~b}$ \\
29 & $8,4 \mathrm{a}$ & $31,9 \mathrm{a}$ & $58,4 \mathrm{a}$ & $149,8 \mathrm{a}$ & $132,8 \mathrm{a}$ & $381,2 \mathrm{a}$ \\
Testemunha & $32,1 \mathrm{~b}$ & $84,9 \mathrm{~b}$ & $199,2 \mathrm{~b}$ & $519,7 \mathrm{c}$ & $628,0 \mathrm{c}$ & $1463,9 \mathrm{c}$ \\
\hline C.V.(\%) & 71,4 & 50,2 & 21,5 & 19,0 & 19,2 & 18,12 \\
DMS & 19,4 & 36 & 31,5 & 73,0 & 84,8 & 178,2 \\
\hline
\end{tabular}

Médias seguidas da mesma letra nas colunas não diferem entre si pelo teste de Duncan a $5 \%$ de probabilidade.

Aos 103 e 108 DAE, observa-se que todos os tratamentos que receberam aplicação do fungicida apresentaram valores médios significativamente menores em relação aos obtidos na testemunha. $\mathrm{Na}$ avaliação realizada aos 115 DAE, o tratamento operando na velocidade máxima da assistência de ar apresentou a menor média de AACPF, diferindo dos demais tratamentos e testemunha. Os demais tratamentos que receberam controle diferiram significativamente da testemunha, porém não diferiram entre si.

Já aos 123 DAE, os tratamentos dotados de assistência de ar nas velocidades de 9, 11 e $29 \mathrm{~km} \mathrm{~h}^{-1}$, apresentaram diferenças significativas do tratamento convencional (sem o uso da assistência de ar) e do tratamento testemunha, com valores de AACPF de 135,2; 159,9 e 132,8 respectivamente (Tabela 3 ).

$\mathrm{Na}$ avaliação do total acumulado da AACPF (Tabela 3), o tratamento com a velocidade máxima do ar gerado pelo ventilador apresentou o menor valor da AACPF. Essa menor AACPF deve-se a um maior volume do fungicida depositado nas superfícies dos folíolos posicionados na parte inferior das plantas (Tabela 2).

No geral, os tratamentos com assistência de ar junto à barra de pulverização apresentaram as menores AACPF. O tratamento sem a utilização da assistência de ar apresentou as maiores AACPF em quase todas as avaliações, evidenciando que a utilização da cortina de ar em pulverizadores terrestre contribui para um melhor desempenho do fungicida no controle da ferrugem asiática em soja.

Godoy \& Cantery (12) testando alguns fungicidas em aplicações preventivas e curativas observaram eficiência de controle da mistura fungicida piraclostrobina + epoxiconazole $\left(65,5+25\right.$ g i.a. ha $\left.{ }^{-1}\right)$ de 93 e $85 \%$, respectivamente aos 2 e 4 dias após a inoculação da doença, evidenciando que este fungicida possui um bom efeito curativo. Os 


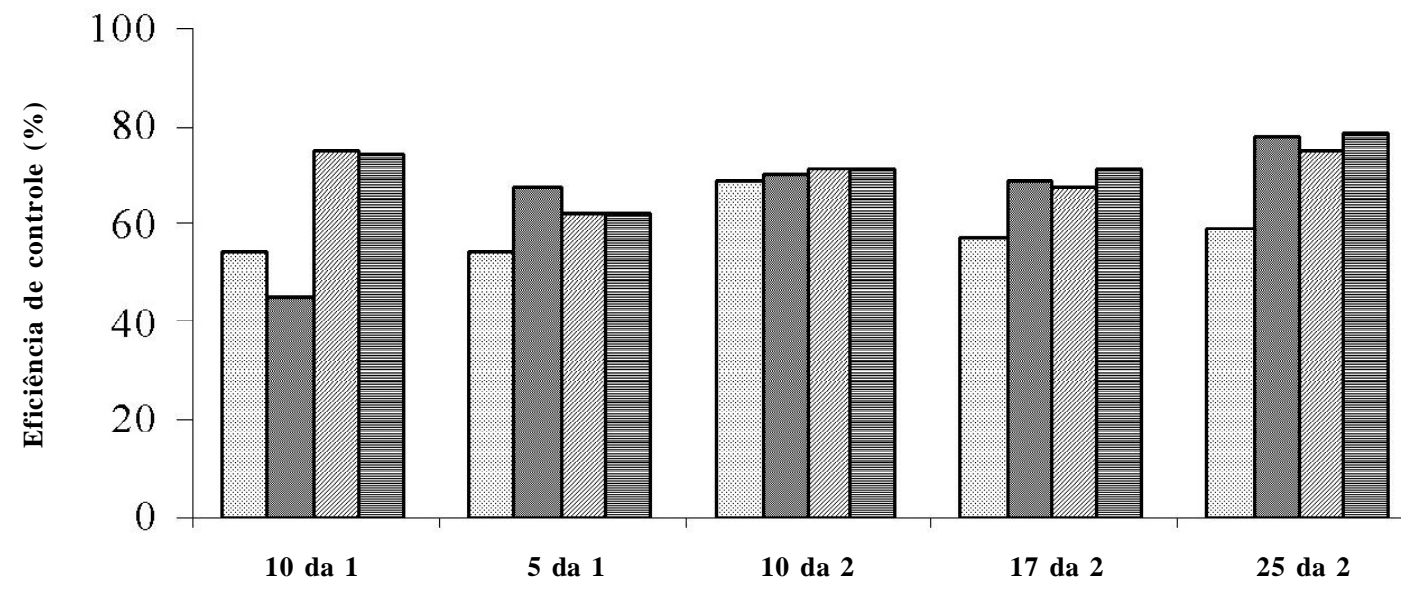

dal : dias após prim eira aplicaçáo da2: dias após segun da aplicação

Dias após aplicação

Figura 1. Eficiência de controle das diferentes velocidades da assistência de ar junto à barra de pulverização utilizando a mistura fungicida piraclostrobina + epoxiconazole. Botucatu-SP, safra 2007/2008.

mesmos autores ressaltaram que os fungicidas pertencentes aos grupos das estrobilurinas e triazóis, sozinhos ou em misturas, são eficientes no controle de P. pachyrhizi.

Em relação à eficiência de controle (Figura 1), os tratamentos com a assistência de ar junto à barra de pulverização apresentaram comportamentos similares, e maior eficiência em comparação ao tratamento sem assistência.

A Figura 2 apresenta as relações entre a produtividade da cultura da soja e a severidade causada por $P$. pachyrhizi. Observa-se que existe uma correlação entre a severidade da doença representada pela AACPF com a produtividade. A produtividade da cultura da soja decresceu à medida que a AACPF aumentou. Cunha \& Ruas (8) obtiveram as maiores produtividades de soja nos tratamentos que apresentaram as menores áreas abaixo da curva de progresso da ferrugem.

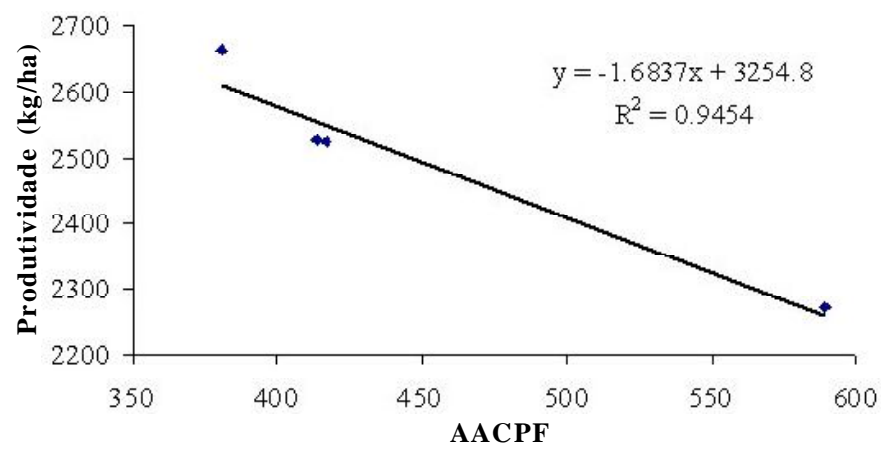

Figura 2. Efeito da severidade de Phakopsora pachyrhizi representada pela área abaixo da curva de progresso da ferrugem (AACPF) na produtividade da cultura da soja. Botucatu-SP, safra 2007/2008.

A média do peso de 1000 grãos e a produtividade em $\mathrm{kg} \mathrm{ha}^{-1}$ após duas pulverizações $\left(R_{2}\right.$ e $\left.R_{5,2}\right)$ com a mistura fungicida piraclostrobina + epoxiconazole $\left(66,5+25 \mathrm{~g}\right.$ i.a. $\left.\mathrm{ha}^{-1}\right)$ utilizando diferentes velocidades da assistência do ar está apresentada na Tabela 4.

A pulverização do fungicida no controle da ferrugem asiática da soja quando este foi aplicado com auxílio da assistência de ar (média da produtividade das três velocidades) promoveu um incremento na produtividade de $64 \%$ enquanto que o tratamento convencional (sem ar) proporcionou um incremento de $45 \%$, ambos em comparação ao
Tabela 4. Efeito de diferentes níveis de assistência de ar na produtividade e massa de 1000 grãos após 2 aplicações ( $\mathrm{R}$ e R ) da mistura fungicida piraclostrobina + epoxiconazole no controle ${ }^{2}$ de $P^{5}{ }^{2}$ pachyrhizi. BotucatuSP, safra 2007/2008.

\begin{tabular}{ccc}
\hline $\begin{array}{c}\text { Velocidade do } \\
\operatorname{Ar}\left(\mathrm{km} \mathrm{h}^{-1}\right)\end{array}$ & $\begin{array}{c}\text { Produtividade } \\
\text { em kg/ha }\end{array}$ & $\begin{array}{c}\text { Peso de } 1000 \\
\text { grãos }(\mathrm{g})\end{array}$ \\
\hline 0 & $2273,5 \mathrm{~b}$ & $161,1 \mathrm{~b}$ \\
9 & $2527,4 \mathrm{ab}$ & $169,8 \mathrm{a}$ \\
11 & $2524,1 \mathrm{ab}$ & $168,8 \mathrm{a}$ \\
29 & $2663,0 \mathrm{a}$ & $169,1 \mathrm{a}$ \\
Testemunha & $1564,1 \mathrm{c}$ & $129,3 \mathrm{c}$ \\
\hline C.V.(\%) & 7,4 & 4,47 \\
DMS & 287,2 & 8,1 \\
\hline
\end{tabular}

Médias seguidas da mesma letra nas colunas não diferem entre si pelo teste de Duncan a $5 \%$ de probabilidade.

tratamento testemunha. Portanto, o desempenho dos produtos fitossanitários no controle dessa doença pode ser melhorado com a adoção dessa tecnologia.

Todos os tratamentos que receberam a aplicação de fungicida obtiveram produtividades significativamente maiores quando comparados à testemunha. Destaca-se o tratamento com a maior velocidade da assistência de ar $\left(29 \mathrm{~km} \mathrm{~h}^{-1}\right)$ que diferiu significativamente do tratamento que recebeu as aplicações de fungicidas sem assistência de ar (convencional) (Tabela 4).

Em relação à massa de 1000 grãos, todos os tratamentos providos da assistência de ar apresentaram diferenças significativas quando comparados ao tratamento convencional e a testemunha (Tabela 4). Os resultados verificados nesse trabalho corroboram com aqueles relatados por Christovam (7) que obteve maior incremento de produtividade quando as plantas foram pulverizadas com auxílio da assistência de ar junto à barra de pulverização.

Cunha et al. (9), estudando o efeito de diferentes pontas e volumes de pulverização no controle da ferrugem asiática da soja, obtiveram acréscimo de produtividade de $34 \%$ em comparação ao tratamento testemunha quando utilizaram a ponta de jato plano API 11002 e volume de $160 \mathrm{~L} \mathrm{ha}^{-1}$. No geral, esses autores observaram resultados semelhantes de produtividade em relação aos verificados nesse trabalho.

Em alvos imóveis, como as folhas da parte inferior das plantas de 
soja, o uso da assistência de ar contribuiu para uma melhor eficiência de controle da ferrugem asiática com o uso de fungicidas, apresentando uma menor severidade da ferrugem nos tratamentos onde se utilizou a assistência de ar junto à barra de pulverização. $\mathrm{O}$ tratamento utilizando a máxima velocidade da assistência de ar promoveu melhor controle da doença com incremento de produtividade quando comparados ao tratamento realizado sem o uso dessa tecnologia (convencional). Esse maior controle deve-se ao fato que a cortina de ar gerada pelo ventilador promoveu maiores depósitos nos folíolos da parte inferior e mediana das plantas de soja. Visto que a doença se inicia pelas folhas do terço inferior das plantas (18) é de grande valia empregar o fungicida nas folhas dessa parte da planta, pois as chances de sucesso de controle dessa doença serão maiores.

Vale lembrar que outros benefícios com o uso dessa tecnologia devem ser considerados como, por exemplo, maiores depósitos e penetração da pulverização, menores perdas por deriva, redução do volume de aplicação e consequentemente uma maior capacidade operacional da máquina são fatores que devem ser levados em consideração na diminuição dos custos do controle fitossanitário e uma menor contaminação do ambiente (19).

A assistência de ar junto à barra de pulverização, nas velocidades de 11 e $29 \mathrm{~km} \mathrm{~h}^{-1}$, resultou em melhores níveis de depósito nos folíolos da parte inferior das plantas de soja.

$\mathrm{O}$ uso da assistência de ar junto à barra de pulverização contribuiu para melhor controle da ferrugem asiática, proporcionando acréscimo na produtividade e peso de 1000 grãos.

\section{REFERÊNCIAS BIBLIOGRÁFICAS}

1. Azevedo, L. A. S. Fungicidas sistêmicos: teoria e prática. Campinas: EMOPI, 2007. 283 p.

2. Bauer, F. C.; Raetano, C. G. Assistência de ar na deposição e perdas de produtos fitossanitários em pulverizações na cultura da soja. Scientia Agrícola, Piracicaba, v. 57, n. 2, p. 271-276, 2000 .

3. Bauer, F. C.; Raetano, C. G. Influência da assistência de ar na barra de pulverização na deposição e penetração da calda em folíolos de feijoeiro. In: Simpósio Internacional de Tecnologia de Aplicação de Agrotóxicos: Eficiência, Economia e Preservação da Saúde Humana e do Ambiente 2., 2001, Jundiaí. Anais. Jundiaí: Instituto Agronômico, Centro de Mecanização e Automação Agrícola, 2001. (1 CDROM).

4. Bauer, F. C.; Almeida, E.; Marques, D. C.; Rossi, T.; Pereira, F. A. R. Deposição de pontas de pulverização AXI 11002 e JA-2 em diferentes condições operacionais, Ciência Rural, Santa Maria, v. 38, n. 6, p. 1610-1614, 2008.

5. Campbell, C. L.; Madden, L. V. Introduction to plant disease epidemiology. New York: John Wiley, 1990. 532 p.

6. Chaim, A.; Valarini, P. J.; Oliveira, D. A.; Morsoleto, R. V.; Pio, L. C. Avaliação de perdas de pulverização em cultura de feijão e tomate. Jaguariúna: Embrapa Meio Ambiente, 1999. 29 p. (Boletim de Pesquisa).
7. Christovam, R. S. Assistência de ar e aplicação em volume baixo no controle da ferrugem asiática da soja. 2008. $68 \mathrm{f}$. Dissertação (Mestrado em Agronomia/Agricultura) - Faculdade de Ciências Agronômicas, Universidade Estadual Paulista, Botucatu.

8. Cunha, J. P. A. R.; RUAS, R. A. A. Uniformidade de distribuição volumétrica de pontas de pulverização de jato plano duplo com indução de ar. Pesquisa Agropecuária Tropical, Goiânia, v. 36, n. 1, p. 61-66, 2006.

9. Cunha, J. P. A. R.; Moura, E. A. C.; Silva-Júnior, J. L.; Zago, F. A.; Juliatti, F. C. Efeito de pontas de pulverização no controle químico da ferrugem da soja. Engenharia Agrícola, Jaboticabal, v. 28, n. 2, p. 283-291, 2008.

10. Fehr, W. R.; Caviness, C. E.; Burmood, D. T.; Pennington, J. S. Stage of development description for soybeans [Glycine max (L.) Merrill]. Crop Science, Madison, v. 11, n. 6, p. 929-931, 1971.

11. Silva, F. A. S.; Azevedo, C. A. V. A new version of the assistatstatistical assistance software. In: World Congress on Computers in Agriculture, 4, Orlando-FL-USA: Anais. Orlando: American Society of Agricultural Engineers, 2006. p. 393-396.

12. Godoy, C. V.; Canteri, M. G. Efeitos protetor, curativo e erradicante de fungicidas no controle da ferrugem da soja causada por Phakopsora pachyrhizi, em casa de vegetação. Fitopatologia Brasileira, Brasília, DF, v. 29, n. 1, p. 97-101, 2004.

13. Godoy, C. V.; Koga, L. J.; Canteri, M. G. Diagrammatic scale for assessment of soybean rust severity. Fitopatologia Brasileira, Brasília, DF, v. 31, n. 1, p. 63-68, 2006.

14. Hislop, E. C.; Western, N. M.; Butler, R. Experimental air-assisted spraying of a maturing cereal crop under controlled conditions. Crop Protection, Amsterdam, v.14, n.1, p.19-26, 1995.

15. Jorgensen, L.; Witt, K. L. Spraying and the impact on the environment: Spraying technique in relation to approval and use of pesticides in Northern Europe. In: Hardi International. Hardi international application technology course 2000. Taastrup, 2000. v. 1, chap. 2, p. 38-48.

16. Raetano, C. G.; Bauer, F. C. Efeito da velocidade do ar em barra de pulverização na deposição de produtos fitossanitários em feijoeiro. Bragantia, Campinas, v. 62, n. 2, p. 329-334, 2003.

17. Raetano, C. G.; Bauer, F. C. Deposição e perdas da calda em feijoeiro em aplicação com assistência de ar na barra pulverizadora. Bragantia, Campinas, v. 63, n. 2, p. 309-315, 2004.

18. Raetano, C. G. Assistência de ar e outros métodos de aplicação a baixo volume em culturas de baixo fuste: a soja como modelo. Summa Phytopathologica, Botucatu, v. 33, supl., p. 105-6, 2007.

19. Stevenson, W. R.; James, R. V. Evaluation of different sprayers technologies for fungicide application to control early and late blights. Vegetable Diseases Control Trials, Wisconsin, p. 21 8, 1997. Disponível em: <http://www.plantpath.wisc.edu/wivegdis>. Acesso em: 15 jun. 2008.

20. Viganó, L. L. S.; Raetano, C. G. Assistência de ar e volumes de aplicação na deposição de calda e no controle do arroz vermelho (Oryza sativa L.). Engenharia Agrícola, Jaboticabal, v. 27, n. 3, p. 734-741, 2007.

21. Yorinori, J. T., Paiva, W. M., Frederick, R. D.; Fernandez, P. F. T. Ferrugem da soja (Phakopsora pachyrhizi) no Brasil e no Paraguai, nas safras 2000/01 e 2001/02. In: Congresso Brasileiro de Soja, 2002, Foz do Iguaçu. Anais. Foz do Iguaçu, Embrapa, 2002. p. 94. 